\title{
Scientific evidence base for transactional analysis in the year 2010
}

\section{(C) 2010 Thomas Ohlsson}

\begin{abstract}
The International Journal of Transactional Analysis Research, IJTAR, has been created to stimulate research and support the continued effort to build a scientific evidence base for transactional analysis (TA). This article is an attempt to locate the starting point for the journal, to identify, evaluate and draw conclusions from what has already been done, and to articulate the existing scientific evidence base for TA in the year 2010.
\end{abstract}

\section{Key Words}

Transactional analysis, research, psychotherapy

\section{Aims}

One purpose of this article is to facilitate new research by making a comprehensive list of existing TA-research available. It has been possible to identify 326 studies between 1963 (Albert Hall on prediction of interpersonal behaviour) and 2010 (including two of those appearing in this issue of IJTAR). The reference list of 326 studies constitutes the bulk of the article. Another purpose is to make the present scientific knowledge about TA visible and understandable. Each included study represents substantial investment of time and scholarship (often years of academic work), and each one deserves careful reading and thought to grasp its conclusions, a task far beyond the ambitions of this article. However, some observations will be presented, especially pertaining to the question of the effectiveness of TA psychotherapy. Generally it may be stated that there already exists a substantial scientific evidence base supporting the usefulness of TA theory and methods in several fields of application, including psychotherapy.

\section{Method}

In a first step a comprehensive list of references, called the Big List, was created. General inclusion criteria were that the studies likely were conducted and/or approved by trained $\mathrm{PhD}$ level researchers, that TA was a major research focus, and that the studies were published. It was assumed that trained researchers have the necessary skills to use appropriate research designs. While the intention was to make an all-inclusive list, it is recognized, with apologies, that qualified existing research may have been omitted due to inadequate search strategies and efforts. This may be particularly true for research in languages other than English and Swedish. The Big List was compiled from several sources:

1. In 1981 Barbara Wilson made a review of all TA research listed in the Dissertation Abstracts International before December 1980. She presented her analysis and also included a reference list organized according to eleven areas of investigation in the Transactional Analysis Journal. Between 1963 and 1980 altogether 124 doctoral dissertations on TA were written and approved, almost all of them at universities in the United States. Although Wilson gave sufficient identification details, author information was omitted, making recognition somewhat difficult. Through cross checking with other available lists it was possible to identify 48 of "Wilson's" studies by author. These studies are included in part one of the present list, which is alphabetically organized according to author. The remaining 76 studies appear in part two, which keeps Wilson's original organization principle.

2. When starting his own dissertation work in the mid 1980s the writer began to compile TA research references from data base searches and other sources. This work was intensified during attempts to get TA therapy officially recognized by the Swedish government in the late 1980s. The resulting lists contained references not available to Wilson.

3. Recently Khalil (2007) searched electronic databases and other sources for evidence of outcomes of TA and identified 97 studies. 
4. Elbing (2007) identified eight TA-psychotherapy studies that he believed met criteria for Evidence Based Medicine evaluation.

5. References to TA research published on the webpage of EATA were searched

(http://www.eatanews.org/research2.htm).

6. All hard copies of Transactional Analysis Journal were finger-tip searched.

7. Colleagues of the editorial board of the IJTAR, and others, were asked for references, particularly in languages other than English.

Entries were sorted into five categories: psychotherapy, counselling, organizational, educational and general (including testing, theory, religion and other areas). In the list each category is indicated by $\mathrm{P}, \mathrm{C}, \mathrm{O}, \mathrm{E}$, or $\mathrm{G}$ immediately after the entry.

In a second step the Big List was searched for research that specifically concerns the effects of TA psychotherapy. In recent years government licensing of psychotherapists and associated funding of psychotherapy have become an issue in many countries. To get approval psychotherapy efficiency needs to be "scientifically" demonstrated. Research has therefore become increasingly important for many TAtherapists. Khalil (2007, p. 20) concluded that for TA psychotherapy "the evidence-base remains scant and of relatively poor quality", and in Sweden TA-therapy was indeed denied recognition by the authorities in the early 1990s due to "lack of research". From TA's point of view the most pressing need for research seems presently to be in the field of psychotherapy. Therefore a second list, the Psychotherapy List, was created. It consists of 88 studies selected from the Big List that are believed to be relevant for the question of the effectiveness of TA psychotherapy. Inclusion criteria were:
1. Articles rated by the author as being research on effects of TA therapy;

2. Articles having been singled out by other investigators as being particularly relevant to research on effects of TA therapy, like articles included in a meta study by Smith, Glass, and Miller (1980), and searches by Elbing (2007) and Khalil (2007).

Twelve of the articles came from categories C, E, or G in the Big List and 76 came from category $P$.

Abstracts or full forms of the 88 psychotherapy studies were then searched for outcomes. In some cases no information was available to the author, but generally it was possible to identify and classify the effectiveness of the TA-therapy studied into one of six categories:

$$
\begin{array}{ll}
+ & \text { TA treatment brought positive changes } \\
\text { - } & \text { TA treatment brought negative changes } \\
\mathbf{0} & \text { TA treatment did not bring any significant changes } \\
? & \text { Outcome results unknown to the author } \\
\mathbf{2} & \text { Second report on study already included in the list } \\
\text { NA } & \text { Not applicable - Results did not concern } \\
& \text { effectiveness of TA therapy. }
\end{array}
$$

One of the symbols $+,-, 0, ?, 2$, and NA appear at the end of each entry in the Psychotherapy List. Studies rated as,+- , and 0 are also marked with *.

\section{Results}

The Big List and the Psychotherapy List are themselves the primary results of this investigation. They are found in Annexes 1 and 2 respectively, which are included as separate documents for ease of later reference. Both lists contain comments by the author. The comments are offered only to pass on the author's limited knowledge of the studies, and the author makes no claims of having made full and systematic reviews of the articles in the lists.

Figure 1. The Big List - Number of TA research studies/year 1963-2010

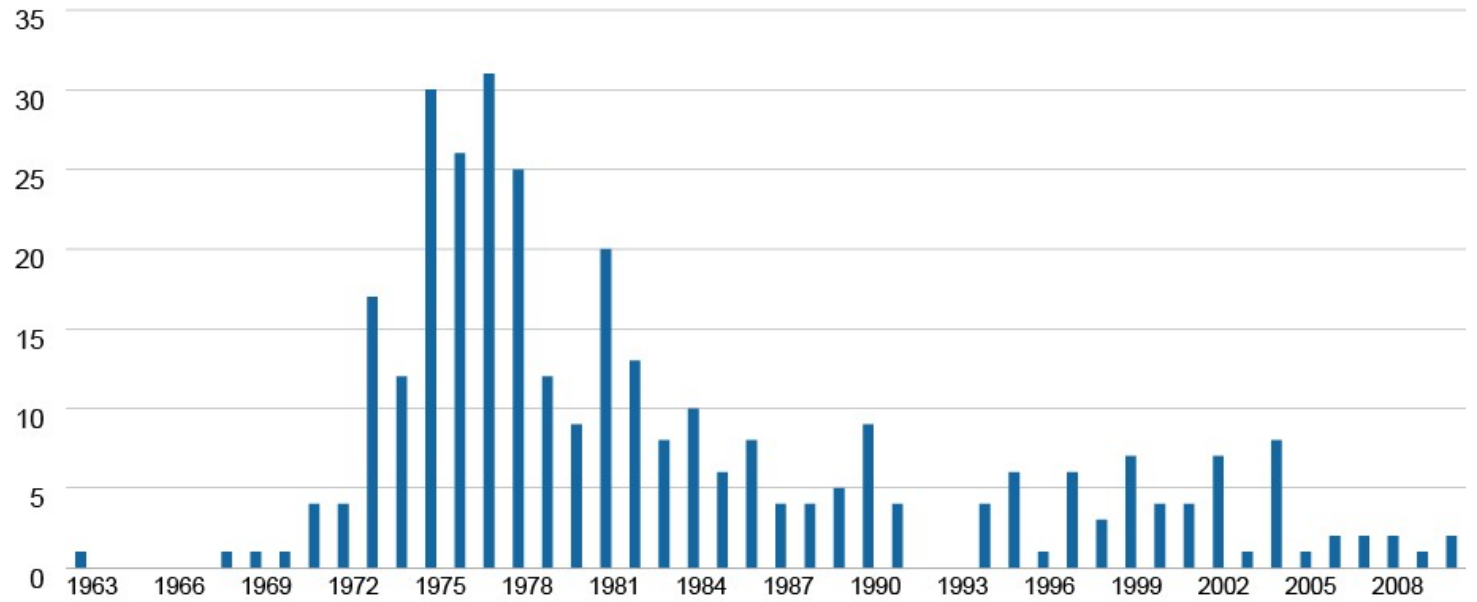


Table 1 shows the number of TA research studies done each year between 1963 and 2010 in the four application fields of TA: psychotherapy, counselling, organizational and educational, as well as how many studies that could be considered general for all fields or didn't fit in any of the four fields so these were classified as General. A graphic representation of the number of studies in different years is shown in Figure 1.

Figure 1 shows that the 1970s and early 1980s were the most active period so far for TA research. Almost all of the research done during that period was done in the United States, and a great deal of it was doctoral dissertations at different universities. Some major studies were also done during this period, notably Jesness' study (1975) at California Youth Authority and a pioneering meta-study by Smith, Glass and Miller (1980). In later years the research production has been lower, and most of the work has been done in Europe.

Figure 2 shows that most research was done in the educational and psychotherapy fields (about 100 studies in each field), and that the organizational and counselling fields generated far less research (15 studies each). It is also noted that about a third of all TA research did not fit into any one of the four standard fields of application. One reason is that some research was on TA theory rather than on applications, like validation of theoretical concepts. Another reason is that there are other areas of application like religion or test development.

It is hardly surprising that there are relatively many psychotherapy studies. Eric Berne was a psychiatrist and psychotherapist, and the official definition of TA, stated in every issue of the Transactional Analysis Journal, is "Transactional analysis is a theory of personality and a systematic psychotherapy for personal growth and social change". The high number of studies in education may depend on the fact that many researchers work at universities and have various teaching processes close at hand. TA's clearly defined theoretical concepts also lend themselves well to teaching, and many TA-therapists teach the concepts to their clients. Sometimes the border between teaching and therapy is not sharp.

The low number of studies in counselling and organization may be more surprising. It is possible that counselling and psychotherapy are not always clearly distinguished and that the resulting helping activity is rather called psychotherapy than counselling, particularly considering Eric Berne's influence. For organizations it is possible that they generally have higher incentives to actually use TA than to study its methods scientifically.
Table 1. The Big List - TA research studies per application field and year.

\begin{tabular}{|c|c|c|c|c|c|c|}
\hline & $\begin{array}{l}\frac{a}{0} \\
\frac{\pi}{0} \\
\frac{5}{0} \\
\frac{0}{0} \\
\frac{0}{0} \\
0\end{array}$ & 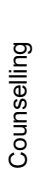 & 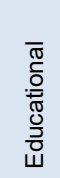 & 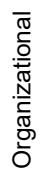 & 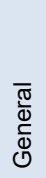 & $\begin{array}{l}\xi \\
\bar{~}\end{array}$ \\
\hline 1963 & 1 & & & & & 1 \\
\hline 1964 & & & & & & \\
\hline 1965 & & & & & & \\
\hline 1966 & & & & & & \\
\hline 1967 & & & & & & \\
\hline 1968 & & & & & 1 & 1 \\
\hline 1969 & 1 & & & & & 1 \\
\hline 1970 & & & & & 1 & 1 \\
\hline 1971 & 1 & & & & 3 & 4 \\
\hline 1972 & 1 & 1 & 1 & & 1 & 4 \\
\hline 1973 & 6 & 3 & 4 & & 4 & 17 \\
\hline 1974 & 1 & 1 & 7 & & 3 & 12 \\
\hline 1975 & 9 & & 13 & 1 & 7 & 30 \\
\hline 1976 & 3 & 2 & 13 & 2 & 6 & 26 \\
\hline 1977 & 9 & 1 & 11 & & 10 & 31 \\
\hline 1978 & 4 & 2 & 9 & 3 & 7 & 25 \\
\hline 1979 & 3 & 1 & 6 & & 2 & 12 \\
\hline 1980 & 2 & & 4 & 1 & 2 & 9 \\
\hline 1981 & 6 & 1 & 6 & 2 & 5 & 20 \\
\hline 1982 & 7 & 1 & 3 & & 2 & 13 \\
\hline 1983 & 3 & 1 & 2 & & 2 & 8 \\
\hline 1984 & 2 & & 1 & 2 & 5 & 10 \\
\hline 1985 & 3 & & 1 & 1 & 1 & 6 \\
\hline 1986 & 2 & & 1 & 2 & 3 & 8 \\
\hline 1987 & 2 & & 1 & & 1 & 4 \\
\hline 1988 & 3 & & 1 & & & 4 \\
\hline 1989 & 2 & & 1 & & 2 & 5 \\
\hline 1990 & 3 & 1 & 1 & & 4 & 9 \\
\hline 1991 & & & 3 & 1 & & 4 \\
\hline 1992 & & & & & & \\
\hline 1993 & & & & & & \\
\hline 1994 & 1 & & 3 & & & 4 \\
\hline 1995 & 2 & & 1 & & 3 & 6 \\
\hline 1996 & & & & & 1 & 1 \\
\hline 1997 & 3 & & 3 & & & 6 \\
\hline 1998 & 2 & & & & 1 & 3 \\
\hline 1999 & 2 & & 1 & & 4 & 7 \\
\hline 2000 & 1 & & & & 3 & 4 \\
\hline 2001 & 3 & & 1 & & & 4 \\
\hline 2002 & 2 & & & & 5 & 7 \\
\hline 2003 & 1 & & & & & 1 \\
\hline 2004 & & & & & 8 & 8 \\
\hline 2005 & & & & & 1 & 1 \\
\hline 2006 & 1 & & 1 & & & 2 \\
\hline 2007 & 2 & & & & & 2 \\
\hline 2008 & 2 & & & & & 2 \\
\hline 2009 & & & 1 & & & 1 \\
\hline 2010 & 1 & & & & 1 & 2 \\
\hline Sum & 97 & 15 & 100 & 15 & 99 & 326 \\
\hline
\end{tabular}




\section{The Psychotherapy List}

The author attempted to read all 88 studies identified as potentially being studies on effects of TA psychotherapy in abstract or in full. Table 2 shows how the 88 studies were rated. In 9 cases abstracts or full articles were not found (marked in the list with?). 14 articles were found not to be relevant, for example when "transactional analysis" did not refer to TA but was used as a term to describe communication in some other theoretical framework (marked as NA). Five studies were second reports on studies already contained in the list, like a doctoral dissertation monograph also being written up as a journal article (2). Of the remaining 60 articles 50 showed significantly positive effects of TA psychotherapy (marked with + ) whereas 10 failed to establish such positive effect (marked with 0 ). No study showed harmful effects (marked with -).

Figure 3 shows that care must be exercised when attempts are made to compile and overview research. $16 \%$ of what from the titles appeared to be effect studies on TA-therapy turned out not to be so, $6 \%$ of the studies were in fact duplicate reports, and the content of $10 \%$ of the studies remain unknown since the writer failed to locate abstracts or articles. But figure 3 also shows that at least $68 \%$ of the presumed effect studies were indeed studies of effects of TA therapy and that more than $80 \%$ of the identified and read effect studies showed positive effects of TA therapy.

Table 2. The Psychotherapy List - 88 studies rated in six categories

\begin{tabular}{ccccccc}
+ & - & $\mathbf{0}$ & $\boldsymbol{?}$ & $\mathbf{2}$ & NA & Sum \\
\hline 50 & 0 & 10 & 9 & 5 & 14 & 88 \\
\hline
\end{tabular}

Altogether 60 studies (marked with * in the Psychotherapy List) were rated as unique studies of effects of TA psychotherapy.

It seems safe to state that there are at least $50 \mathrm{PhD}$-level studies with professional research designs that have found positive effects of TA psychotherapy. There are also at least 10 such studies that have failed to find positive effects of TA psychotherapy.
Figure 2. The Big List - Percentages of studies per application field
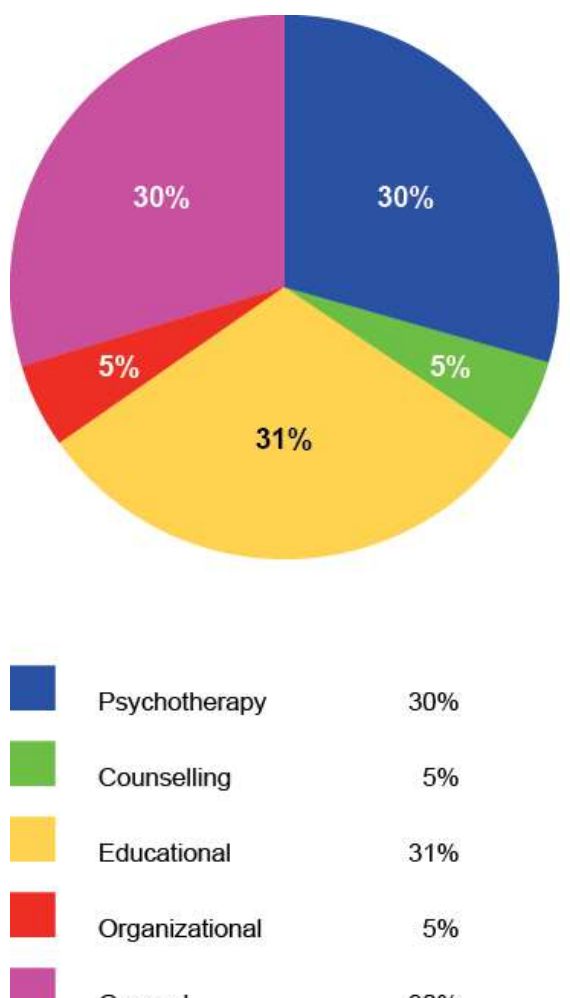

General

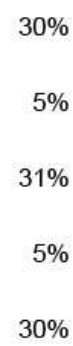

$30 \%$
Figure 3. The Psychoterapy List - Ratings of 88 studies
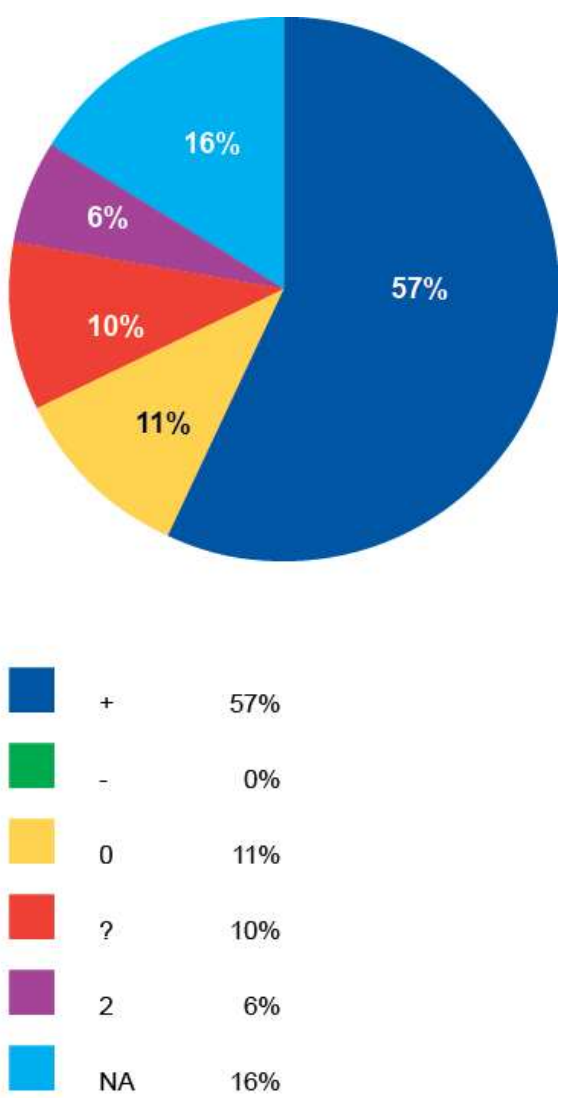


\section{Discussion}

\section{Evaluation}

With a few exceptions all the research reported here was done during the forty years that have passed since Eric Berne's death in 1970. It is clear that TA has inspired considerable research in a wide range of human endeavours, from Hall's (1963) study of predictable interpersonal behaviour to Kornyeyeva's (2010) study of the role of existential positions for acculturation of young immigrants. How is this research to be understood and evaluated?

First, it should be noted that this TA research is here, it exists. Anyone who believes that TA is scantily researched is advised to read through Annex 1 and contemplate the scientific knowledge that lies stored behind each title. None of it is "dead" or "out of date" - it is all here, living contemporary knowledge for anyone who cares to read it. It is doubtful if any one person can today claim personal knowledge and overview of all existing TA-research. Projects to analyze and draw conclusions from the existing pool of TA-research are in themselves worthy research projects, with benefits for TA practitioners as well as future researchers.

Second, it appears that, possibly with a few exceptions, the studies were done by professionally trained researchers. A doctoral dissertation at a recognized university is proof of independent capabilities as a researcher. One skill of a doctoral level researcher is the ability to choose relevant research designs for different types of research projects. It may therefore be assumed that the studies included here hold professional quality and have suitable research designs. As is further commented on below, there is no such thing as a "golden standard" that research projects should be evaluated against.

Third, no destructive or harmful effects of TA were noted during the gathering of the material. Admittedly no systematic attempt was made to evaluate the research findings of all 326 studies. But in the 88 studies believed to concern psychotherapy, positive effects were frequent and negative effects were absent (one study indicating negative effects, Olson et al 1981, is commented on below).

\section{Some remarks on "scoping exercises" of TA research}

This article may be seen as a "scoping exercise" of existing TA research: the author attempted to gather up and somehow "taste" the content of the metaphorical research box marked "TA flavour". With bigger eyes than mouth he wanted to taste as much as possible and then write a review to share with all. Should this review be considered as scientific research in its own right? In the mind of the author the answer is no. While the review is based on searches for scientific "data" (previous research), the attempts to classify and gain new knowledge from the data are too loose to be considered scientific. As has been pointed out, the Big List is the new achievement of this report, and the writer's adjoining words should be heeded using scientifically critical attitude.

To place the presented lists and annotations in the context of earlier attempts to summarize TA psychotherapy research a few comments on Khalil (2007) and Elbing (2007) are offered. Khalil ( $p$ 2-3) identified 19 studies on her "master list". Studies "were included provided they concerned the application of TA intervention, demonstrated a reasonably clear, replicable method, and had used pre- and post test measure to gauge effect, any reasonable attempt at measurement was deemed sufficient for inclusion". Her evaluation of the 19 studies that she included (out of 97 identified by searches) were (p 18): "Of the evidence identified, even the 19 studies included in the review, the quality of research was poor, and the findings from these 19 studies are not necessarily meaningful."

On examination, Khalil's conclusions seem unduly harsh. Her "scoping exercise", like the present one, was too loosely conceived to justify claims of scientific conclusions. She reported 34 studies identified for potential inclusion and a further 82 studies noted as research in education, business and $\mathrm{PhD}$ research plus 6 excluded studies on "TA measures" ( $p$ 7). What appeared as $34+82+6=122$ studies were actually 97 studies as some $\mathrm{PhD}$ studies appeared twice as business and education research. Her master list was not consistent with her stated criteria. She included a meta study by Smith et al (1980), but she excluded all nine TA-studies that Smith et al used to determine the effect size of TA-therapy. She did not include studies that fulfilled her criteria (like Ohlsson 2002) and she included studies that did not meet her criteria (like Greene 1998). Her initial view of existing TA research (p.2) discounted readily available information: "evidence of TA outcomes appears to be largely anecdotal and composed of case studies..." Her three conclusions (p. 20) that TA "is probably as effective as other therapies", "the evidence base remains scant and of relatively poor quality", and "what evidence base exists is insular and not subjected to the quality reviews of the wider academic and health communities" were not connected in a systematic way to her data. Like in the present exercise, Khalil's basic achievement was to create a comprehensive list of references relating to the effectiveness of TA psychotherapy. Though her list is part of the knowledge base for the Big List here, it is not identical to the Psychotherapy List, and it is interesting to note that both attempts located similar numbers of studies on the effectiveness of TA psychotherapy (97 and 88 respectively).

Elbing (2007) attempted to identify eight "model" TA studies that met the demands of a hierarchy of research designs called Evidence Based Medical (EBM) criteria, a variation of the doctrine that Randomized Control 
Trial (RCT) studies are the golden standard of psychotherapy effect research. Unfortunately it seems that two of his three "best" studies (Dumas et al 1995, Glick et al 1975) were not relevant as they did not study effects of TA psychotherapy. Dumas et al, despite a title that included "transactional analysis" was not a study of TA, and in Glick et al the focus was not on evaluating the TA part of the treatment, which was minor.

The third study at the top of Elbing's hierarchy was Olson et al (1981). This study may be used as an example of the necessity for careful reading of full research reports before accepting what "research has shown". In Khalil (2007) this study was included in the "master list" of 19 studies and it was summarized: "Of the four treatments; a. MDT standard treatment; $b$. behavioural intervention; c. TA; d. b. and c. combined; TA performed worst of all groups on all measurements." In many ways this study seems methodologically like a model RCT-design study, including control group, randomization, precise measurements and publication in a respected source, the Journal of Consulting and Clinical Psychology. The reported results appeared negative for TA. However, careful reading of the full article gave this writer a different picture. An established in-patient hospital treatment program for alcoholics was studied in terms of reduction of alcohol consumption after the program. The program was based on medical and Alcoholics Anonymous milieu therapy principles. Small additional programs of 1) behaviour modification, or 2) TA, or 3) combined behaviour modification and TA were compared for effect. In the mid range follow up time period the TA group had a significantly higher alcohol consumption, but in the long range follow up there was no significant difference. All variations of the basic treatment program, as well as the basic standard program, were successful in reducing alcohol consumption. The combined group actually showed the lowest alcohol intake figures. The writers of the research were also leaders of the behaviour modification program, while the transactional analyst (one person) came in as an outsider in the program. The wordings of the writers favoured their own approach, which may not be surprising. This research report may fruitfully be read by anyone who wants to sharpen his/her ability to make an independent assessment of research reports. In the present Psychotherapy List this study has been rated as +(-) for TA, listed under + , since in the end also the TA program contributed to a positive result, even if the "TA patients" had a higher alcohol consumption during a certain phase.

\section{Design considerations - the "golden standard" myth}

What kind of research is now needed in TA? As noted above, there is a further need for research on the effectiveness of TA psychotherapy. This need is largely political and economic as a means for TA psychotherapists to be legally recognized. There is also a never-ending need for research on all possible aspects of TA, from theory validation to application processes and outcomes. Before considering possible research projects, some reflections on research design may be relevant.

In the interest of diversified and high quality research one particular current scientific trend might be questioned: The myth of the Randomized Control Trial (RCT) being the "golden standard" of science.

Scientific knowledge should have high reliability and high validity. It should not be subject to wishes or preferences in the researcher or anyone else. It should, as far as possible, be "objective" and generally true. It should also be relevant to what is being studied. Research is a way to ask questions of "Nature" and then proceed to get answers that are unknown at the outset. Many strategies for research designs have been developed to bring out the answers. Suitability of the designs depends on the questions asked and the knowledge sought. Life and nature is far too complex to permit one single avenue for all occasions but, striving for simplicity, many "only ways" have been proposed at various times. In the olden days a Chinese farmer, who wished to know what kind of weather to expect for the harvest, knew that the only way to find out was to formulate the question, then heat a tortoise shell and let a trained "scientist" read the answer in the way the shell cracked. Nowadays many people "know" that the only way to get "real" scientific knowledge is to use RCT designs. This is particularly so in testing medical drugs.

Without going into technicalities of RCT designs it can be stated that RCT designs are strongly advocated by authorities that regard psychotherapy as a kind of "talking pill". Authorities want "scientific proof" that drugs or psychotherapies work to guide their decisions on allocating public money. "Research has shown..." is a good argument. And "research" in this context has become equivalent with "RCT-design research", which has been marketed as "the golden standard" or "the only way" for reliable scientific truth. Recently "the golden standard" status has been challenged from inside the medical establishment by Michael Rawlins (2008) in his Harveian oration. For statistical and other reasons the RCT-norm for drug testing was put into question. The article is highly recommended for those who believe that psychotherapy studies, including TA studies, must use RCT-designs to be credible. It is not so. Suitable research designs should be used, depending on questions asked and answers sought, and the RCTdesign is one of many plausible designs. In the end the responsibility to evaluate any research remains with the reader, or the decision maker. 


\section{Ideas about new TA research}

While the presented TA research is substantial, of professional quality, and with a general tendency to find TA-therapy beneficial, large studies with extensive budgets are sparse (Jesness 1975 and maybe Lieberman et al 1973 being exceptions). The time may now be ripe to carry through major research projects to study the effects of TA psychotherapy. Novey's (2002) international study was a beginning of limited reach and universality.

A worldwide research project to study effects of TA therapy seems conceivable as a joint project of the major international TA organizations. Such a project might require centralized leadership from a researcher group at a university of good standing and have a budget for several years. A research design meeting scientific and political recognition criteria could be worked out, and fieldwork (psychotherapy) could be carried out in different countries. The international TA organizations could contribute to the research budget and to connect field workers (TA therapists) and researchers. The organizations would of course have no influence on the outcomes. This type of study has not been carried out so far and is just emerging as a possibility considering TA's continued international development.

Also smaller, well-designed studies that build on existing knowledge will be vital for TA's continued development and credibility. TA researchers have up to this point shown creativity and initiative in studying aspects of TA that have been of interest to them. Hopefully this will go on, shedding more light on the usefulness of TA in many walks of human life. TA research should not, as all research should not, succumb to political or personal goals of certain groups of people. Curiosity and quest for new knowledge is a powerful personal motive to engage in research, and this motive should be encouraged.

Scientific research is an activity that is carried out by trained researchers. The established education to become a researcher is the doctorate, a university degree. Research as a discipline is only recently becoming focused on as part of TA training and examinations. Future TA research therefore depends heavily on the interest of university trained researchers to do TA research. There seem to be at least three ways in which such interest can be promoted:

1. Transactional analysts and TA-organizations can actively establish ties with universities and get TA into the normal curricula of many university courses. University students can learn early that TA is a viable field for research;

2. Transactional analysts can be encouraged to engage in doctorate studies, and transactional analysts with doctoral degrees can be encouraged to do research;

3. TA-organizations can take initiatives to conduct research projects like the project suggested above.

TA is by now well beyond its pioneering days. There are many transactional analysts who can look back on life long careers as "transactional analysts", and there are many people, all over the world, who come away from introductory courses in TA (the TA 101) with "aha"insights about themselves and their lives.

Hmm, wonder why?

Thomas Ohlsson PhD is a Teaching and Supervising Transactional Analyst (Psychotherapy) and an externally placed researcher at the Department for Clinical psychology, Psychological Institution, Lund University, Sweden. He can be contacted at thomas@livsterapi.se

\section{References}

Dumas, J.E., LaFreniere, P.J., Serketich, W.J. (1995). "Balance of power": A transactional analysis of control in mother-child dyads involving socially competent, aggressive, and anxious children. Journal of Abnormal Psychology 104 (1), 104-113.

Elbing, U. (2007). A search for transactional analysis studies according to Evidence Based Medicine (EBM) criteria, EATA Newsletter 90 (Oct)

Glick, I.D., Hargreaves, W.A., Raskin, M., Kutner, S.J. (1975). Short versus long hospitalization: A prospective controlled study. Results for schizophrenic inpatients. American Journal of Psychiatry 134, 385-390.

Green, G. (1988). Analysis of research on the effectiveness of transactional analysis for improving marital relationships: Towards close encounters of the single kind. Transactional Analysis Journal 18, 238-248.

Hall, A. (1963). Prediction of Interpersonal Behavior by Berne's Ego State Psychology. University of Portland.

Jesness, C.F. (1975). Comparative effectiveness of behavioral modification and transactional analysis programs for delinquents. Journal of Consulting and Clinical Psychology $43,758-79$.

Khalil, E., Callaghan, P., James, N. (2007). Transactional analysis: A scoping exercise for evidence of outcome. Report prepared for the Berne Institute. The University of Nottingham, School of Nursing.

Korneyeyeva, L. (2010). Authoritarian Socialization Experience and Acculturation Dysfunction among Young Immigrants to Western Europe: the Role of a Negative Existential Position. In Press. 
Lieberman, M.A., Yalom, I.D., Miles, M.B. (1973). Encounter groups: First Facts. New York: Basic Books.

Novey, T. (2002). Measuring the effectiveness of transactional analysis: An international study. Transactional Analysis Journal 32, 8-24.

Ohlsson, T. (2002). Effects of transactional analysis psychotherapy in therapeutic community treatment of drug addicts. Transactional Analysis Journal 32, 153-177.

Olson, R.P., Ganley, R., Devine, V.T., Dorsey, G.C. (1981). Long-term effects of behavioral versus insight-oriented therapy with inpatient alcoholics. Journal of Consulting and Clinical Psychology, 48, 866-877.
Rawlins, M. (2008). De Testimonio - On the evidence for decisions about use of therapeutic interventions. London: Royal College of Physicians.

www.rcplondon.ac.uk/pubs/contents/304df931-2ddc-4a54894e-e0cdb03e84a5.pdf

Smith, M.L., Glass, G.V., Miller, T.I. (1980). The benefits of psychotherapy. Baltimore: The John Hopkins University Press.

Wilson, B.D. (1981). Doctoral dissertations on TA 1963-1980. Transactional Analysis Journal 11, 194-202. 